TIP Periodica Polytechnica

Transportation Engineering

42(1), pp. 27-35, 2014

DOI: $10.3311 /$ PPtr.7260

http://www.pp.bme.hu/tr/article/view/7260

Creative Commons Attribution (i)

RESEARCH ARTICLE

\section{Development of a new method} for planar-frame structure examination in commercial vehicle design

\author{
Péter Harth / Pál Michelberger
}

RECEIVED 14 October 2013; ACCEPted 14 January 2014

\section{Abstract}

In this paper planar-frame structure with general load is introduced. These structures can be supported one or more symmetry planes. In automotive industry the symmetry gives opportunity for reduction during vehicle design process. The planar structures with planar and perpendicular load are examined with $\sigma$ and $\Sigma$ point methods. Furthermore coefficients of the compatibility matrix and location of $\sigma$ and $\Sigma$ points are represented when the structure have zero, one or more symmetry planes.

\section{Keywords}

Planar-frame structure $\cdot \sigma$ and $\Sigma$ method $\cdot$ symmetry $\cdot$ reduction in commercial vehicle design

\section{Péter Harth}

Department of Automobiles and Vehicle Manufacturing, Budapest University of Technology and Economics,

Stoczek u. 4., H-1111 Budapest, Hungary

e-mail: harth.peter@auto.bme.hu

Pál Michelberger

Department of Vehicle Elements and Vehicle- Structure Analysis, Budapest University of Technology and Economics,

Múegyetem rkp. 3-9., H-1111 Budapest, Hungary

\section{Introduction}

This paper deals with planar-frame structure analysis. The main purpose of this paper is to reduce the number of equations using symmetry, and to give advantage to the planar-frame structures which have symmetry plane(s).

The frame structures are significant in road-vehicle chassis and rail bogie design. The main loads in the frame are caused by weight force, longitudinal and lateral acceleration, driveline torque. (Trencséni and Palkovics, 2011). The planar-frame structure calculation is difficult because of cyclic integrals and variables (See nomenclatures). The planar-frame structures have the following features.

- The frame beam cross section middle line forms a closed planar graph.

- The cross section has at least one principal axis, which is perpendicular to the plane.

- The curvatures of the curved beam sections are generally mild.

- The corners are infinitely rigid, small and short sections compared to the overall size of the frame.

Deformations caused by the normal and shear forces could be negligible compared to the bending and torsion resulting deformation in the classical method (Bieck, 1927; Erz, 1957; Fabry, 1952; Fekete, 1973; Kherndl, 1883; 1884; Michelberger and Sályi, 1969; Palotás, 1951; Schwertner, 1950; Sutter, 1947).

In the following, six internal load components are taken into consideration applying the principle of work. The stress distributions in the cross sections, caused by the warp torsion and shear are neglected. These must be kept in mind in case of thinwall structures. The most generally used planar-frame structure in vehicle design is the rectangular-shaped frame. There the number of symmetry planes can be zero, one, two, three or more. In these frames the sections have the following characteristic parameters: $l$ section length, $I$ bending inertia, $I$ torsion inertia, $E$ Young modulus, $G$ Shear modulus, $A$ cross section area. In general case the section is not managed as symmetric structure. The planar structure can only be symmetric if it has at least two opposite sections which have the same mentioned features. 


\section{Planar-frame structure loads in classical method}

The planar-frame structure for planar load was worked out by Antal Kherndl in the $19^{\text {th }}$ century and it is called " $\sigma$-point method". This method neglects the deformations caused by the normal and shear loads (Kherndl, 1883; 1884). The planar-frame structure for perpendicular load was examined by Béla Sályi who worked out the dual pair of the $\sigma$-point method in the end of the 20th century, which is called " $\Sigma$-point method". This method neglects the deformation caused by the shear load (Sályi, 1966).

Both methods use statically determined basic system frame and the cut is not in the line of the frame, but at an inner point, which is in contact to the frame with infinitely rigid beams (Fig. 1).

The six internal loads are collected in Tab.1.

The matrix coefficients of the compatibility equations are denoted by $\delta_{i k}$, where $i, k=\{1,2,3,4,5,6\}$. The indices $i, k=\{1,2,3\}$ are used for the planar loads and $i, k=\{4,5,6\}$ are used for the perpendicular loads. If the frame is planar, the planar and perpendicular loads are divided into two orthogonal groups, so $\delta_{i k}$ is zero if $i=\{1,2,3\}$ and $k=\{4,5,6\}$. In the $x y$ plane the $\sigma$ point can be located, where $\delta_{i k}$ is zero if $i, k=\{1,2,3\}$ and $i \neq k$. These conditions result that the frame's "principal axes" point to the same directions as it was supposed with the direction of unit internal loads. Continuing this process, in the $x^{\prime} y^{\prime}$ plane a $\Sigma$ point can be located, where $\delta_{i k}=0$, if $i, k=\{4,5,6\}$ and $i \neq k$. In general case the $\sigma$ and $\Sigma$ points are located in different positions causing more complex and time-consuming calculation. The $z$ and $z$ ' axes usually are parallel.

The Kherndl-Sályi methods replaced the original beams with sliced beams, which were realized as physical beams. The inner forces in the cross sections were calculated by the principle of work. It is simply shown that there is no change in the calculation if the slice is in different position from task to task (Sutter, 1947). (Fig. 2-7).

The $\sigma$ and $\Sigma$ points are located in the plane of the frame, but usually are located in a different position and the coordinate system can be different as well. The matrix coefficient of the compatibility equation, in case of $s$ is the arc length along the frame (1-3).

$$
\begin{aligned}
& \delta_{11}=\oint \frac{m_{1}^{2} \mathrm{~d} s}{I_{1} E}+\oint \frac{n_{1}^{2} \mathrm{~d} s}{A E}+\oint \beta_{1} \frac{q_{1}^{2} \mathrm{~d} s}{A G} \\
& \delta_{22}=\oint \frac{m_{2}^{2} \mathrm{~d} s}{I_{1} E}+\oint \frac{n_{2}^{2} \mathrm{~d} s}{A E}+\oint \beta_{1} \frac{q_{2}^{2} \mathrm{~d} s}{A G} \\
& \delta_{33}=\oint \frac{m_{3}^{2} \mathrm{~d} s}{I_{1} E}
\end{aligned}
$$

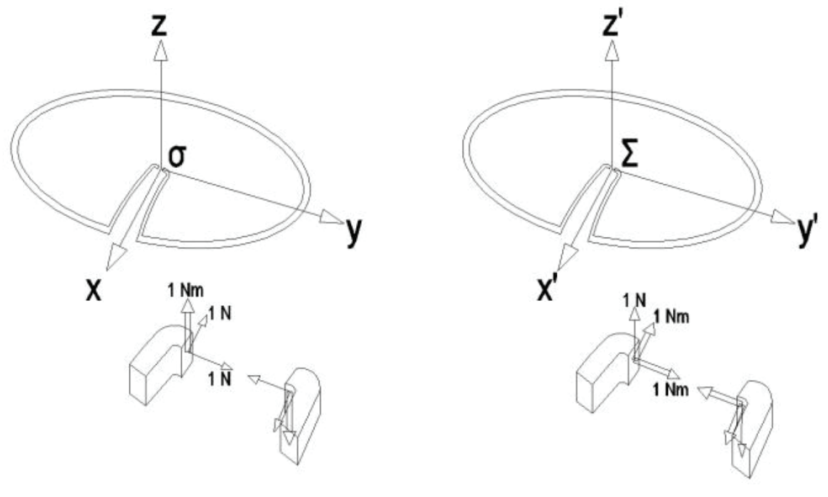

Fig. 1. Representation of $\sigma$ point (left) and $\Sigma$ point (right)

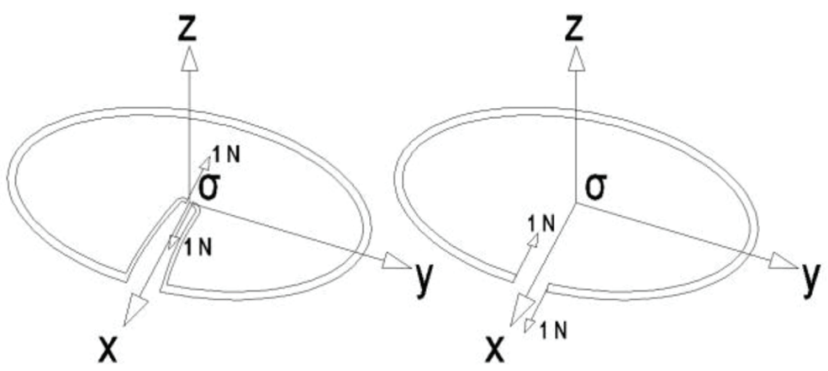

Fig. 2. Equivalent loads caused by $X_{I}$ force

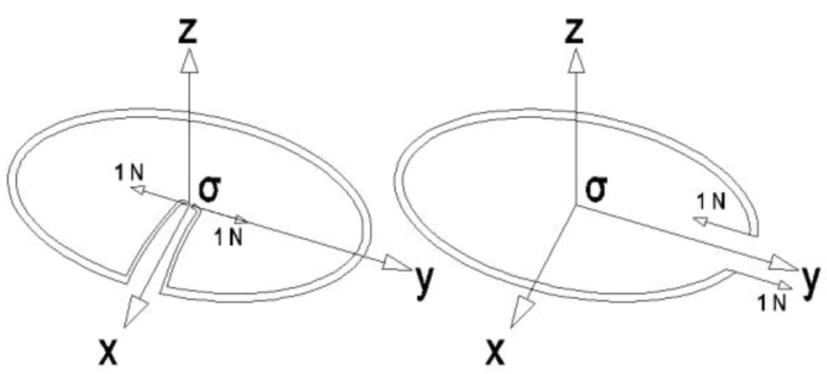

Fig. 3. Equivalent loads caused by $X_{2}$ force

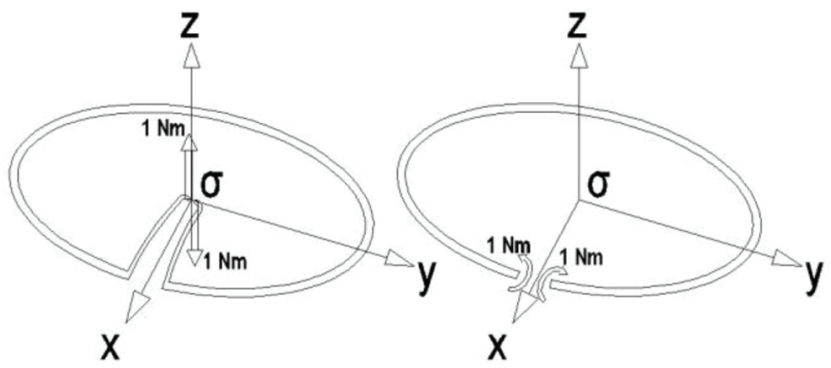

Fig. 4. Equivalent loads caused by $X_{3}$ force

Tab. 1. Six unit internal loads

\begin{tabular}{ccccccc}
\hline $\mathrm{i}$ & 1 & 2 & 3 & 4 & 5 & 6 \\
\hline$X_{i}$ & $1[\mathrm{~N}]$ & $1[\mathrm{~N}]$ & $1[\mathrm{Nm}]$ & $1[\mathrm{Nm}]$ & $1[\mathrm{Nm}]$ & $1[\mathrm{~N}]$ \\
\hline
\end{tabular}




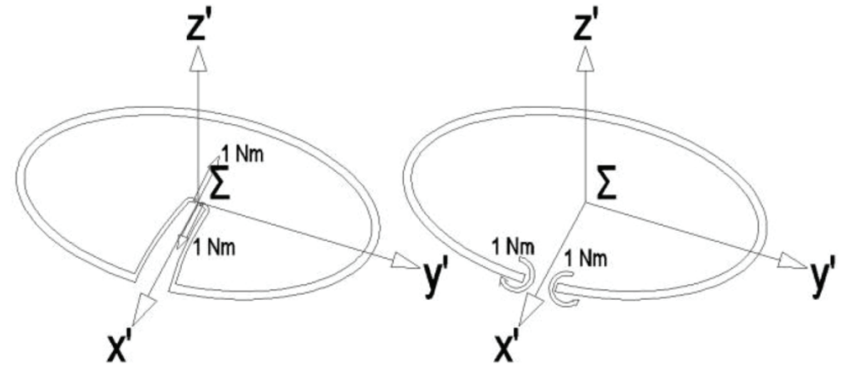

Fig. 5. Equivalent loads caused by $X_{4}$ force

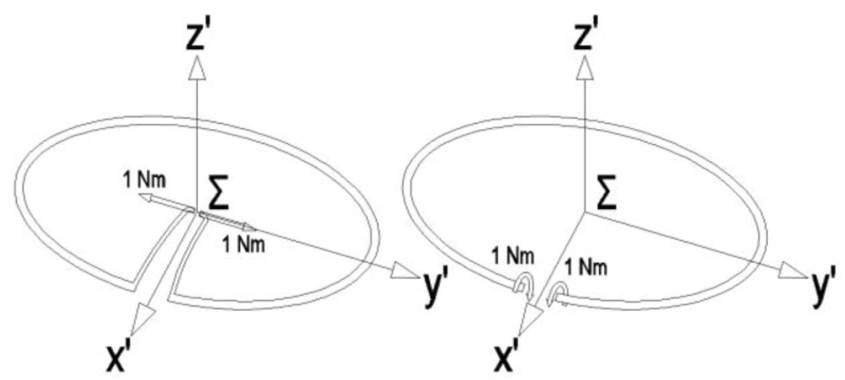

Fig. 6. Equivalent loads caused by $X_{5}$ force

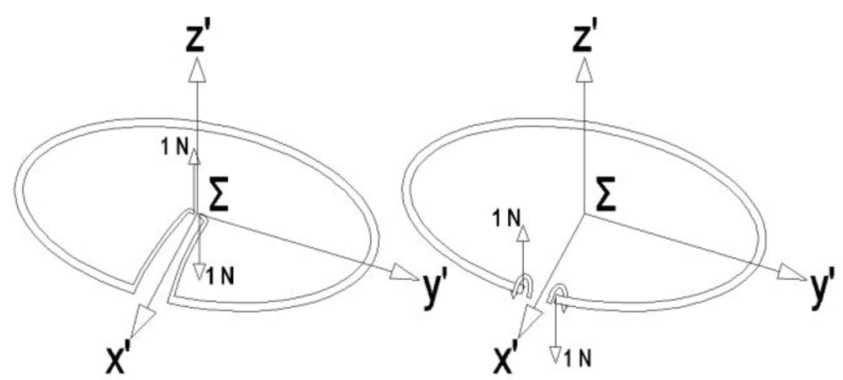

Fig. 7. Equivalent loads caused by $X_{6}$ force

The coefficients with mixed indices (4-6):

$$
\begin{aligned}
& \delta_{12}=\oint \frac{m_{1} m_{2} \mathrm{~d} s}{I_{1} E}+\oint \frac{n_{1} n_{2} \mathrm{~d} s}{A E}+\oint \beta_{1} \frac{q_{1} q_{2} \mathrm{~d} s}{A G} \\
& \delta_{13}=\oint \frac{m_{1} m_{3} \mathrm{~d} s}{I_{1} E}+\oint \frac{n_{1} n_{3} \mathrm{~d} s}{A E}+\oint \beta_{1} \frac{q_{1} q_{3} \mathrm{~d} s}{A G} \\
& \delta_{23}=\oint \frac{m_{2} m_{3} \mathrm{~d} s}{I_{1} E}+\oint \frac{n_{2} n_{3} \mathrm{~d} s}{A E}+\oint \beta_{1} \frac{q_{2} q_{3} \mathrm{~d} s}{A G}
\end{aligned}
$$

\begin{tabular}{cccc}
\hline $\mathrm{i}$ & $\mathrm{m}_{\mathrm{i}}(\mathrm{s})$ & $\mathrm{n}_{\mathrm{i}}(\mathrm{s})$ & $\mathrm{q}_{\mathrm{i}}(\mathrm{s})$ \\
\hline 1 & $-y$ & $-\cos \alpha$ & $\sin \alpha$ \\
2 & $x$ & $-\sin \alpha$ & $-\cos \alpha$ \\
3 & 1 & 0 & 0 \\
\hline
\end{tabular}

Tab. 3. Units loads in case of perpendicular load

\begin{tabular}{cccc}
\hline $\mathrm{i}$ & $\mathrm{m}_{\mathrm{i}}(\mathrm{s})$ & $\mathrm{t}_{\mathrm{i}}(\mathrm{s})$ & $\mathrm{q}_{\mathrm{i}}(\mathrm{s})$ \\
\hline 4 & $\sin \alpha^{\prime}$ & $\cos \alpha^{\prime}$ & 0 \\
5 & $-\cos \alpha^{\prime}$ & $\sin \alpha^{\prime}$ & 0 \\
6 & $-y \sin \alpha^{\prime}-x \cos \alpha^{\prime}$ & $-y \cos \alpha^{\prime}+x \sin \alpha^{\prime}$ & 1 \\
\hline
\end{tabular}

and finally the coefficients with mixed indices (10-12).

$$
\begin{aligned}
& \delta_{45}=\oint \frac{m_{4} m_{5} \mathrm{~d} s}{I_{2} E}+\oint \frac{t_{4} t_{5} \mathrm{~d} s}{I_{t} G} \\
& \delta_{46}=\oint \frac{m_{4} m_{6} \mathrm{~d} s}{I_{2} E}+\oint \frac{t_{4} t_{6} \mathrm{~d} s}{I_{t} G} \\
& \delta_{56}=\oint \frac{m_{5} m_{6} \mathrm{~d} s}{I_{2} E}+\oint \frac{t_{5} t_{6} \mathrm{~d} s}{I_{t} G}
\end{aligned}
$$

The equations can be added in other way, if the unit loads are written as in the tables below (Tab. 2-7).

With this the coefficients are collected in Tab. 4-7.

In case of suitable choice of $x y z$ ( $x^{\prime} y^{\prime} z$ ') coordinate axes, the mixed indices coefficients can be zero and thus six statically indetermined equations can be easily calculated. Because of the cyclic integral, the general curvature planar-frame structure's "principal axis" and "centre of gravity" calculations are difficult. Here the centre of the gravity means the location of the $\sigma$ and $\Sigma$ points. The calculation task could be easier, if the frame has at least one symmetry plane. In case of one symmetry plane, the "principal axes" are given and there is no need to calculate the first or second coordinate of $\sigma$ and $\Sigma$ points. If the structure has two symmetry planes the "principal axes" and $\sigma$

Tab. 2. Unit loads in case of planar load 
or $\Sigma$ points coincide. Three symmetry planes do not give extra information about the location of $\sigma$ or $\Sigma$ points, and the number of "principal axes" are infinite.

\section{Calculation in general case}

For general shape frame calculation the "principal axes" and locations of $\sigma$ and $\Sigma$ points are time-consuming. Instead of $x y$ ( $\left.x^{\prime} y^{\prime}\right)$ coordinate system, the frame analysis is done in the $\xi \eta$ arbitrary direction coordinate system. Both of these systems have the same origins, $\sigma$ or $\Sigma$ points. The $x y$ ( $\left.x^{\prime} y^{\prime}\right)$ axes are rotated with $\gamma\left(\gamma^{\prime}\right)$ angles. The elementary $\mathrm{d} s$ sections are defined with $r\left(r^{\prime}\right)$ local vectors and $\varphi\left(\varphi^{\prime}\right)$ angles. The main purpose is to determine the $\gamma\left(\gamma^{\prime}\right)$ angles where $x y\left(x^{\prime} y^{\prime}\right)$ are principal axes (Fig. 8).

The value of $\delta_{12}$ is zero in $x y$ coordinate system, if the $x y$ coordinate axes point into the principal axes directions (13). In the $\xi \eta$ coordinate system it cannot be zero, because $\xi \eta$ axes are not principal axes (14). If the $\gamma$ and $\gamma^{\prime}$ angle is chosen correctly in the the $\xi \eta$ coordinate system, the $x y$ axes can be principal axes.

$$
\begin{aligned}
\delta_{12}= & -\oint x y \frac{\mathrm{d} s}{I_{1} E} \\
& -\oint \sin (\alpha-\gamma) \cos (\alpha-\gamma)\left(\frac{\beta_{1}}{A G}-\frac{1}{A E}\right) \mathrm{d} s=0 \\
\delta_{12}= & -\oint \xi \eta \frac{\mathrm{d} s}{I_{1} E}-\oint \sin \alpha \cos \alpha\left(\frac{\beta_{1}}{A G}-\frac{1}{A E}\right) \mathrm{d} s \neq 0
\end{aligned}
$$

Similarly to planar load, in case of perpendicular load the first mixed indices coefficient $\delta_{45}$ is zero (15), if the $x^{\prime} y^{\prime}$ coordinate axes point into the suitable direction. (Just the geometrical symmetry is required in (15) because of trigonometric functions.)

$$
\begin{aligned}
& \delta_{45}=\oint \sin \left(\alpha^{\prime}-\gamma^{\prime}\right) \cos \left(\alpha^{\prime}-\gamma^{\prime}\right)\left(\frac{1}{I_{t} G}-\frac{1}{I_{2} E}\right) \mathrm{d} s=0 \\
& \delta_{45}=\oint \sin \alpha^{\prime} \cos \alpha^{\prime}\left(\frac{1}{I_{t} G}-\frac{1}{I_{2} E}\right) \mathrm{d} s \neq 0
\end{aligned}
$$

The $\gamma$ and $\gamma$ ' angles are determined with the following equations:

$$
\begin{aligned}
& A \operatorname{tg}^{2} \gamma+B \operatorname{tg} \gamma-A=0 \\
& A^{\prime} \operatorname{tg}^{2} \gamma^{\prime}+B^{\prime} \operatorname{tg} \gamma^{\prime}-A^{\prime}=0
\end{aligned}
$$

From these equations, two $\gamma$ (denoted by $\gamma_{1}, \gamma_{2}$ ) and two $\gamma^{\prime}$ (denoted by $\gamma_{1}^{\prime}, \gamma_{2}^{\prime}$ ) angles are given, which are perpendicular $\left(\gamma_{1} \perp \gamma_{2}\right.$ and $\left.\gamma^{\prime}{ }_{1} \perp \gamma_{2}^{\prime}\right)$.
Tab. 4. Matrix coefficients in case of planar load

\begin{tabular}{cccc}
\hline Comp & $\mathrm{M}$ & $\mathrm{N}$ & $\mathrm{Q}$ \\
\hline$\delta_{11}$ & $\oint y^{2} \frac{\mathrm{d} s}{I_{1} E}$ & $\oint \cos ^{2} \alpha \frac{\mathrm{d} s}{A E}$ & $\oint \beta_{1} \sin ^{2} \alpha \frac{\mathrm{d} s}{A G}$ \\
$\delta_{22}$ & $\oint x^{2} \frac{\mathrm{d} s}{I_{1} E}$ & $\oint \sin ^{2} \alpha \frac{\mathrm{d} s}{A E}$ & $\oint \beta_{1} \cos ^{2} \alpha \frac{\mathrm{d} s}{A G}$ \\
$\delta_{33}$ & $\oint \frac{\mathrm{d} s}{I_{1} E}$ & 0 & 0 \\
\hline
\end{tabular}

Tab. 5. Matrix mixed coefficients in case of planar load

\begin{tabular}{cccc}
\hline Comp & $\mathrm{M}$ & $\mathrm{N}$ & $\mathrm{Q}$ \\
\hline$\delta_{12}$ & $-\oint x y \frac{\mathrm{d} s}{I_{1} E}$ & $\oint \sin \alpha \cos \alpha \frac{\mathrm{d} s}{A E}$ & $-\oint \beta_{1} \sin \alpha \cos \alpha \frac{\mathrm{d} s}{A G}$ \\
$\delta_{13}$ & $-\oint y \frac{\mathrm{d} s}{I_{1} E}$ & 0 & 0 \\
$\delta_{23}$ & $\oint x \frac{\mathrm{d} s}{I_{1} E}$ & 0 & 0 \\
\hline
\end{tabular}

Tab. 6. Matrix coefficients in case of perpendicular load

\begin{tabular}{cccc}
\hline Comp & $\mathrm{M}$ & $\mathrm{T}$ & $\mathrm{Q}$ \\
\hline$\delta_{44}$ & $\oint \sin ^{2} \alpha^{\prime} \frac{\mathrm{d} s}{I_{2} E}$ & $\oint \cos ^{2} \alpha^{\prime} \frac{\mathrm{d} s}{I_{t} G}$ & 0 \\
$\delta_{55}$ & $\oint \cos ^{2} \alpha^{\prime} \frac{\mathrm{d} s}{I_{2} E}$ & $\oint \sin ^{2} \alpha^{\prime} \frac{\mathrm{d} s}{I_{t} G}$ & 0 \\
$\delta_{66}$ & $\oint\left(x \cos \alpha^{\prime}+y \sin \alpha^{\prime}\right)^{2} \frac{\mathrm{d} s}{I_{2} E}$ & $\oint\left(x \sin \alpha^{\prime}-y \cos \alpha^{\prime}\right)^{2} \frac{\mathrm{d} s}{I_{t} G}$ & $\oint \beta_{2} \frac{\mathrm{d} s}{A G}$ \\
\hline
\end{tabular}

Tab. 7. Matrix mixed coefficients in case of perpendicular load

\begin{tabular}{cccc}
\hline Comp & $\mathbf{M}$ & $\mathbf{T}$ & $\mathbf{Q}$ \\
\hline$\delta_{45}$ & $-\oint \sin \alpha^{\prime} \cos \alpha^{\prime} \frac{\mathrm{d} s}{I_{2} E}$ & $\oint \sin \alpha^{\prime} \cos \alpha^{\prime} \frac{\mathrm{d} s}{I_{t} G}$ & 0 \\
$\delta_{46}$ & $-\oint \sin \alpha^{\prime}\left(x \cos \alpha^{\prime}+y \sin \alpha^{\prime}\right) \frac{\mathrm{d} s}{I_{2} E} \oint \cos \alpha^{\prime}\left(x \sin \alpha^{\prime}-y \cos \alpha^{\prime}\right) \frac{\mathrm{d} s}{I_{t} G}$ & 0 \\
$\delta_{56}$ & $\oint \cos \alpha^{\prime}\left(x \cos \alpha^{\prime}+y \sin \alpha^{\prime}\right) \frac{\mathrm{d} s}{I_{2} E} \oint \sin \alpha^{\prime}\left(x \sin \alpha^{\prime}-y \cos \alpha^{\prime}\right) \frac{\mathrm{d} s}{I_{t} G}$ & 0 \\
\hline
\end{tabular}




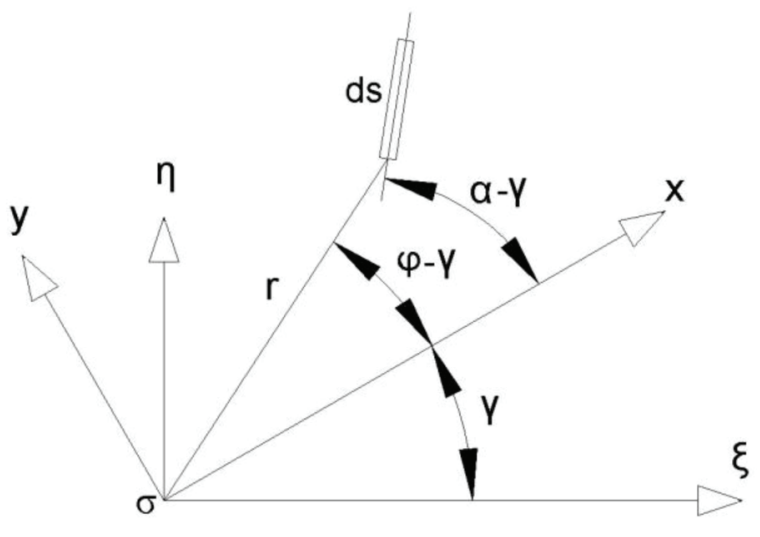

Fig. 8. The basic $\xi \eta$ and rotated $x y$ coordinate systems

The $A$ and $B$ coefficients are given below:

$$
\begin{aligned}
& A=-\oint \xi \eta \frac{\mathrm{d} s}{I_{1} E}-\oint \sin \alpha \cos \alpha\left(\frac{\beta_{1}}{A G}-\frac{1}{A E}\right) \mathrm{d} s \\
& B=\oint\left(\eta^{2}-\xi^{2}\right) \frac{\mathrm{d} s}{I_{1} E}+\oint\left(\sin ^{2} \alpha-\cos ^{2} \alpha\right)\left(\frac{\beta_{1}}{A G}-\frac{1}{A E}\right) \mathrm{d} s \\
& A^{\prime}=-\oint \sin \alpha^{\prime} \cos \alpha^{\prime}\left(\frac{1}{I_{t} G}-\frac{1}{I_{2} E}\right) \mathrm{d} s \\
& B^{\prime}=\oint\left(\sin ^{2} \alpha^{\prime}-\cos ^{2} \alpha^{\prime}\right)\left(\frac{1}{I_{t} G}-\frac{1}{I_{2} E}\right) \mathrm{d} s
\end{aligned}
$$

Rectangular-shaped frames have the following features on all sections:

$$
\begin{aligned}
& \sin (\alpha-\gamma) \cos (\alpha-\gamma)=0 \\
& \sin \left(\alpha^{\prime}-\gamma^{\prime}\right) \cos \left(\alpha^{\prime}-\gamma^{\prime}\right)=0
\end{aligned}
$$

The next step of the investigation is to determine the location of $\sigma$ and $\Sigma$ points. The coefficients $\delta_{13}$ and $\delta_{46}$ are zero if the $x$ or $x$ ' coordinate axes are on the symmetry axis. If the $\sigma$ or $\Sigma$ points are on the $x$ or $x$ ' coordinate axis, the task is to calculate only the $x$ or $x$ ' coordinate. Furthermore the third mixed indices coefficients $\delta_{23}$ and $\delta_{56}$ are zero if the $y$ or $y$ ' coordinate axes are on the symmetry axis and it is needed to calculate only the $y$ or $y$ ' coordinate.

\section{Calculations with symmetry plane(s)}

In general case (without any symmetry) the task is leading to six simple equations if the $x y z$ or $x y^{\prime} y$ ' coordinate systems are known. The $\sigma$ and $\Sigma$ points mostly are in different positions, furthermore $x$ and $x^{\prime}, y$ and $y^{\prime}$ coordinate axes are not parallel. This means that there is need to determine the principal axes and locations of $\sigma$ or $\Sigma$ points without any symmetry support. It must be examined whether the deformation caused by normal and shear loads are negligible. If not, (13) and (15) must be applied. The tables below show how many compatibility equations must be determined in different number of symmetries for the analysis. The unknowns are signed with "•" symbol (see Tab. 8) and the given unknowns (where there is no need for calculation) with " $\bigcirc$ " symbol.

\subsection{Rectangular-shaped structures with one symmetry plane}

The rectangular-shaped frame structure with one symmetry plane is the first step in the reduction process. If the structure had not any symmetry, it would cause a large number of equations and it would not be possible to reduce them. The frame has the following $\alpha$ angles in order: $0^{\circ}, 180^{\circ}-\alpha, 180^{\circ}$ and $\alpha$, if the first section is principal axis. In case of rectangular-shaped section between two opposite sides there is $180^{\circ}$ difference.

With this consideration, the simplified mixed indices matrix coefficients are:

$$
\delta_{12}=\delta_{45}=0
$$

In case of one symmetry plane the second argument is zero in (13), so the deformation caused by the normal and shear load is zero thus the "principal axes" are real principal axes.

Because of the symmetry plane, one of the $\sigma$ or $\Sigma$ point's coordinates is given. At the first column $y$ axis is principal axis, so only the $y$ coordinates must be calculated. At the second column $x$ axis is principal axis, so only the $x$ coordinates must be calculated (see Tab. 9).

\subsection{Rectangular-shaped structures with two symmetry planes}

It is worth dealing with symmetry or antisymmetry of load, which can reduce the computational work. The rectangularshaped frame with two symmetry planes has two pair sections with the same features. The $\alpha$ angles are in order $0^{\circ}, 90^{\circ}, 180^{\circ}$ and $270^{\circ}$. The statically indetermined inner forces can be written with six independent equations and do not cause difficulty to solve them. In case of two or more symmetry axes, the symmetry does not divide into six groups, but eight orthogonal groups. However, there are two statically determined groups, thus there is no need to take them into consideration. With this consideration, the simplified mixed indices matrix coefficients are:

$$
\begin{aligned}
& \delta_{13}=\delta_{23}=0 \\
& \delta_{46}=\delta_{56}=0
\end{aligned}
$$

Because of the two symmetry planes, $\sigma$ or $\Sigma$ is given and the two statically determined independent equations can be solved easily. Those are equations with a single unknown. In the tables they are denoted by “॰” symbol (see Tab.10). 


\subsection{General shape structures with three or more symmetry planes}

The general shape frame structure occasionally can be found in vehicle. The $\sigma$ or $\Sigma$ points are located in the symmetry planes section. There is no need to calculate them. The "principal axes" can be chosen without any difficulty.

\section{Conclusions}

This paper showed that the symmetry usage during the commercial vehicle design process can be applied to reduce the governing equations. The planar-frame structures can be divided into four groups. The first group contains those structures where there is no symmetry at all; they are called general planar-frame structures. The "principal axis" (in the classical method) is not a real principal axis. The frame structures with one symmetry plane are in the second group. There is opportunity here for reduction in contrast with the first group. The $\sigma$ or $\Sigma$ points are located on the symmetry axis. The deformations caused by normal and shear loads are zero and the "principal axes" are real principal axes (the deformation is calculated, but given zero). The third group contains those structures where the calculation can be supported with two symmetry planes. This gives the opportunity to reduce the number of descriptive equations. The $\sigma$ and $\Sigma$ points, and the principal axes are coincident. The last group contains those structures which have three or more symmetry planes. These structures have infinite number of principal axes position, but do not give extra advantage in calculation.

\section{Appendices}

It is important to define the sign rule. Both the force and torque vectors which are acting in the $\sigma$ or $\Sigma$ points point to $+x$, $+y$, or $+z$ axis and the free sliced section is located in the first quarter. The bending torque is positive if the shirred side is the outside in case of planar load. In case of perpendicular load the torque positive if the shirred side is located on the $+z$ side. The torsion is positive if the free end of the frame is turning out. The shear is positive if the shear vector points out from the frame. In case of perpendicular load the shear is positive if the vector points at $+z$. And finally the normal load positive if it is tensile.

a.) Substitution of torsion stiffness (for two end bounded, prismatic thin-wall beam, $(E r z, 1957))$

$$
T=-E I_{\omega} \varphi^{I I I}+G I_{T} \varphi^{I}
$$

where:

$$
\varphi=\frac{T l}{G I_{T}}\left(1-\frac{\operatorname{th} \frac{\omega l}{2}}{\frac{\omega l}{2}}\right), \omega=\sqrt{\frac{G I_{T}}{E I_{\omega}}},
$$

Tab. 8. The required coordinates and unknowns in case of zero symmetry (general case)

\begin{tabular}{ccccccc}
\hline \multirow{2}{*}{ Planar load } & x & y & y & 1 & 2 & 3 \\
& $\bullet$ & $\bullet$ & $\bullet$ & $\bullet$ & $\bullet$ & $\bullet$ \\
Perp. load & $x^{\prime}$ & $y^{\prime}$ & y' & 4 & 5 & 6 \\
& $\bullet$ & $\bullet$ & $\bullet$ & $\bullet$ & $\bullet$ & $\bullet$ \\
\hline
\end{tabular}

Tab. 9. The required coordinates and unknowns in case of one symmetry plane (A-Antisymmetric, S-Symmetric)

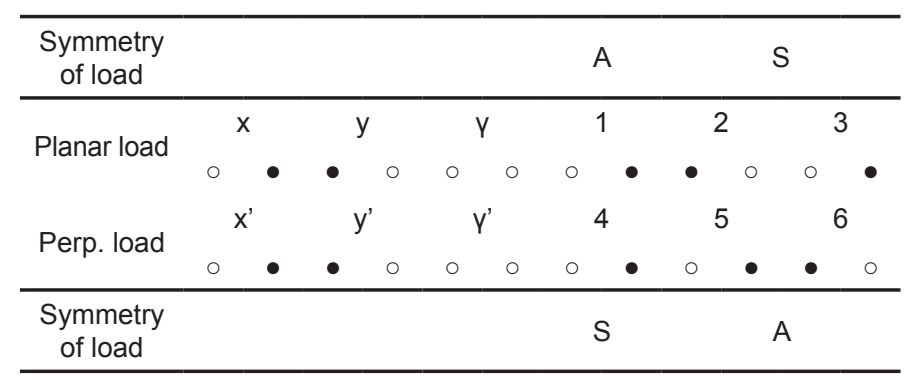

Tab. 10. The required coordinates and unknowns in case of two symmetry

\begin{tabular}{|c|c|c|c|c|c|c|c|}
\hline $\begin{array}{l}\text { Symmetry } \\
\text { of load }\end{array}$ & & & & AS & SA & SS & $\mathrm{AA}$ \\
\hline \multirow{2}{*}{ Planar load } & $x$ & $\mathrm{y}$ & $\mathrm{Y}$ & 1 & 2 & 3 & Det. Eq. \\
\hline & $\circ$ & ० & ० & $\bullet$ & $\bullet$ & $\bullet$ & $\bullet$ \\
\hline \multirow{2}{*}{ Perp. load } & $x^{\prime}$ & $y^{\prime}$ & $V^{\prime}$ & 5 & 4 & Det. Eq. & 6 \\
\hline & $\circ$ & $\circ$ & $\circ$ & $\bullet$ & $\bullet$ & $\bullet$ & $\bullet$ \\
\hline $\begin{array}{l}\text { Symmetry } \\
\text { of load }\end{array}$ & & & & AS & SA & SS & $\mathrm{AA}$ \\
\hline
\end{tabular}
planes

Warp stiffness: $\mathrm{EI}_{\omega}\left[\mathrm{m}^{6}\right]$

$G I_{T}^{*}=\frac{G I_{T}}{\left(1-\frac{\operatorname{th} \frac{\omega l}{2}}{\frac{\omega l}{2}}\right)}$

b.) Generalization of basic system

(Original basic system)

$$
\begin{aligned}
& D x+d=0 \rightarrow x=-D^{-1} d=\left(B^{T} R B\right)^{-1} B^{T} R a \\
& \rightarrow x=-D^{-1} d=\left(B^{T} R B\right)^{-1} B^{T} R a
\end{aligned}
$$

where: a: Load from external load

B: Load from unit load

R: Spring matrix of the frame

(Transformed basic system) 
$\mathrm{Dx}+\mathrm{Td}=0$ and $\mathrm{x}=\mathrm{T}^{\mathrm{T}} \mathrm{y}$, if $\operatorname{det} \mathrm{T} \neq 0$ and

$\mathrm{x}=\mathrm{T}^{\mathrm{T}} \mathrm{y}$, if $\operatorname{det} \mathrm{T} \neq 0$

$\mathrm{TDT}^{\mathrm{T}} \mathrm{y}+\mathrm{Td}=0$

$\mathrm{TB}^{\mathrm{T}} \mathrm{RBT}^{\mathrm{T}} \mathrm{y}+\mathrm{TB}^{\mathrm{T}} \mathrm{Ra}=0$

$\mathrm{TB}^{\mathrm{T}}=\overline{\mathrm{B}}^{\mathrm{T}}$ and $\overline{\mathrm{B}}=\mathrm{BT}^{\mathrm{T}}$

$\overline{\mathrm{B}}^{\mathrm{T}} \mathrm{R} \overline{\mathrm{B}} \mathrm{y}+\overline{\mathrm{B}} \mathrm{Ra}=0 \rightarrow \mathrm{y}=-\left(\overline{\mathrm{B}}^{\mathrm{T}} \mathrm{R} \overline{\mathrm{B}}\right)^{-1} \overline{\mathrm{B}}^{\mathrm{T}} \mathrm{Ra}$

where: $d=B^{T} R a$

$\mathrm{D}=\mathrm{B}^{\mathrm{T}} \mathrm{RB}$

The final load:

$1=a+B x=a+B T^{T} y=a+\bar{B} y$

This makes the using of different basic systems in one task possibly. It was used by Sutter for the first time.

c.) Substitution of cyclic integral in digital form

(Argyris and Kelsey, 1963)

$\mathrm{d}=\mathrm{B}^{\mathrm{T}} \mathrm{Ra}$

$\mathrm{D}=\mathrm{B}^{\mathrm{T}} \mathrm{RB}$

$b_{1}=[\overbrace{m_{1}(1)_{B}, m_{1}(1)_{E}, q_{1}(1), n_{1}(1)}^{1 \text { stsection }}, \overbrace{m_{1}(2)_{B}, m_{1}(2)_{E}, q_{1}(2), n_{1}(2)}^{\text {2ndsection }}, \ldots$,

$b_{2}=[\overbrace{m_{2}(1)_{B}, m_{2}(1)_{E}, q_{2}(1), n_{2}(1)}^{\text {1stsection }}, \overbrace{m_{2}(2)_{B}, m_{2}(2)_{E}, q_{2}(2), n_{2}(2), \ldots,}^{\text {2ndsection }}]$

$b_{3}=[\overbrace{m_{3}(1)_{B}, m_{3}(1)_{E}, q_{3}(1), n_{3}(1)}^{1 \text { stsection }}, \overbrace{m_{3}(2)_{B}, m_{3}(2)_{E}, q_{3}(2), n_{3}(2)}^{\text {2ndsection }}, \ldots$,

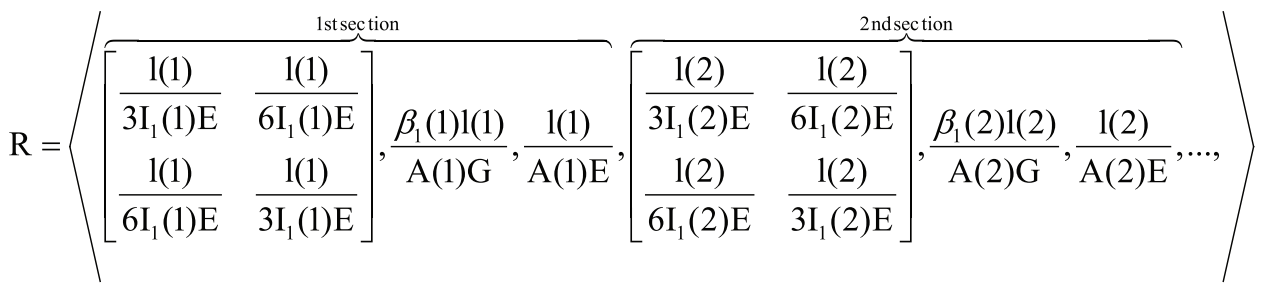

$\mathrm{b}_{4}=[\overbrace{\mathrm{m}_{4}(1)_{\mathrm{B}}, \mathrm{m}_{4}(1)_{\mathrm{E}}, \mathrm{t}_{4}(1), \mathrm{q}_{4}(1)}^{\text {1stsection }}, \overbrace{\mathrm{m}_{4}(2)_{\mathrm{B}}, \mathrm{m}_{4}(2)_{\mathrm{E}}, \mathrm{t}_{4}(2), \mathrm{q}_{4}(2)}^{\text {2ndsection }}, \ldots$, 


$$
\begin{aligned}
& \mathrm{b}_{5}=[\overbrace{\mathrm{m}_{5}(1)_{\mathrm{B}}, \mathrm{m}_{5}(1)_{\mathrm{E}}, \mathrm{t}_{5}(1), \mathrm{q}_{5}(1)}^{1 \text { 1stsection }}, \overbrace{\mathrm{m}_{5}(2)_{\mathrm{B}}, \mathrm{m}_{5}(2)_{\mathrm{E}}, \mathrm{t}_{5}(2), \mathrm{q}_{5}(2)}^{\text {2ndsection }}, \ldots,] \\
& \mathrm{b}_{6}=[\overbrace{\mathrm{m}_{6}(1)_{\mathrm{B}}, \mathrm{m}_{6}(1)_{\mathrm{E}}, \mathrm{t}_{6}(1), \mathrm{q}_{6}(1)}^{\text {1stsection }}, \overbrace{\mathrm{m}_{6}(2)_{\mathrm{B}}, \mathrm{m}_{6}(2)_{\mathrm{E}}, \mathrm{t}_{6}(2), \mathrm{q}_{6}(2)}^{\text {2ndsection }}, \ldots,
\end{aligned}
$$

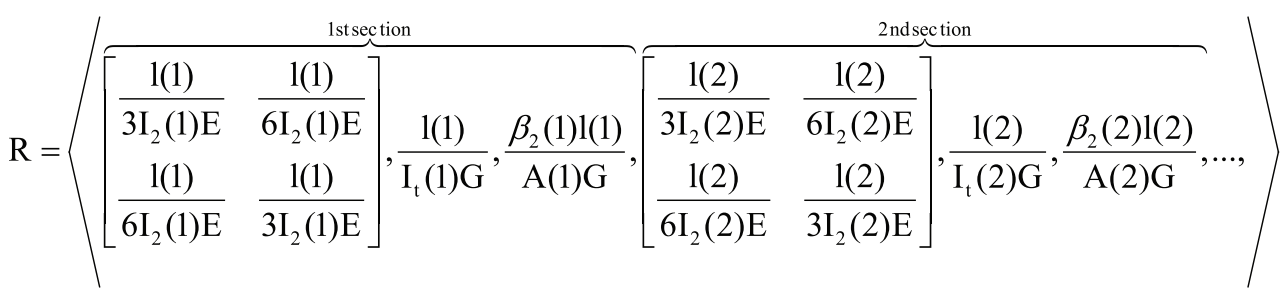

and $\beta=\frac{A}{I^{2}} \int_{A}\left(\frac{S}{v}\right)^{2} \mathrm{~d} A$ (shape coefficient)

\section{Nomenclature}

$\sigma \quad$ :Origin of $x y z$ coordinate system

$\Sigma \quad$ :Origin of $x^{\prime} y^{\prime} z$ ' coordinate system

$d s \quad$ :Elementary examined section [m]

$i, k \quad$ :Indices for applied unit load [-]

$m_{i}(s)$ :Bending torque on section $\mathrm{s}[\mathrm{Nm}]$

$n_{i}(\mathrm{~s})$ :Normal load on section $\mathrm{s}[\mathrm{N}]$

$q_{i}(\mathrm{~s}) \quad$ :Shear load on section $\mathrm{s}[\mathrm{N}]$

$t_{i}(\mathrm{~s}):$ Torsion torque on section $\mathrm{s}[\mathrm{Nm}]$

$A(\mathrm{~s}):$ :Cross section area $\left[\mathrm{m}^{2}\right]$

$E(\mathrm{~s}) \quad$ :Young modulus [MPa]

$G(\mathrm{~s})$ :Shear modulus [MPa]

$I_{l}(\mathrm{~s})$ :Inertia (bending, planar load) $\left[\mathrm{m}^{4}\right]$

$I_{2}$ (s) :Inertia (bending, perp. load) $\left[\mathrm{m}^{4}\right]$

$I_{t}(\mathrm{~s}) \quad$ :Inertia (torsion) $\left[\mathrm{m}^{4}\right]$

$\beta_{l}(\mathrm{~s})$ :Shape coefficient (planar) [-] $\beta_{2}(\mathrm{~s})$ :Shape coefficient (perp.) [-]

$l \quad:$ Section length [m]

$\gamma \quad$ :Angle between $x y$ and $\xi \eta$ coord. systems $\left[{ }^{\circ}\right]$

$\gamma^{\prime} \quad$ :Angle between $x^{\prime} y^{\prime}$ and $\xi \eta$ coord. systems $\left[{ }^{\circ}\right]$

$\alpha(\mathrm{s}) \quad$ :Angle between $+x$ axis and examined section longitudinal axis $\left[^{\circ}\right]$

$\alpha^{\prime}$ (s) :Angle between $+x^{\prime}$ axis and examined section longitudinal axis $\left[^{\circ}\right]$

$r(\mathrm{~s}) \quad$ :Local vector for ds section in $x y$ coordinate system [m]

$r$ '(s) :Local vector for ds section in $x^{\prime} y^{\prime}$ coordinate system [m]

$\varphi(\mathrm{s}) \quad$ :Angle between $r$ local vector and $\xi$ axis $\left[^{\circ}\right]$

$\varphi^{\prime}(\mathrm{s})$ :Angle between $r$ ' local vector and $\xi$ axis $\left[{ }^{\circ}\right]$

\section{References}

1 Argyris J. H., Kelsey S., Modern fuselage analysis and the elastic aircraft. Butterworths, London (1963).

DOI: $10.1002 /$ zamm.19640440713

2 Bieck H., Berechnung des Rahmenträgersystems in der Seitenwanden der neuen eisernen Wagen der Berliner Hochbahn. Glasers Annalen, 12, 175-180, 183-196 (1927).

3 Erz K., Über die durch Unebenheiten der Fahrbahn hervorgerufene Verdrehung von Strassenfahrzeugen, Automobiltechnische Zeitschrift, 59, 89-96, 163-170, 345-347, 371-375 (1957).

4 Fabry Ch. W., Leichtbau Probleme und ihre statische Erfassung im Wagonbau, Glasers Annalen, 76(9), 6-210 (1952).

5 Fekete A., A modellválasztás kérdései jármüalvázak sztatikai számitásánál. Budapest (1973)

6 . Magyar Mérnök- és Építész Egylet Közleménye, 17(6), 248-270 (1883).

7 Kherndl A., A statikailag határozatlan reakciójú tartók elméletéhez II. Magyar Mérnök- és Építész Egylet Közleménye, 18(2), 65-79 (1884).

8 Michelberger P., Sályi B., Sik elrendezésü zárt keretek erőjátékának vizsgálata általános terhelésnél. MTA Szilárdságtani kollokvium előadásainak gyüjteménye, Budapest, 145-154 (1969).

9 Palotás L., Keretek elmélete és számitása. Közlekedési Kiadó, Budapest (1951).

10 Sályi B., Sikbeli zárt keresztmetszetek egyes különleges eseteinek vizsgálata. Budapest (1966).

11 Schwertner A., Vasbetonszerkezetek sztatikája. Építőipari Könyvés Lapkiadó Vállalat, Budapest (1950). 
12 Sutter K., Zur Berechnung selbsttragendet Eisenbahnkasten. Wirtschaft und Technik im Transport, 70 (1947).
13 Trencséni B., Palkovics L., Driveline torque observer for heavy duty vehicle. Periodica Polytechnica Transportation Engineering, 39(2), 91-97 (2011).

DOI: $10.3311 /$ pp.tr.2011-2.08 